\title{
Narrativa
}

\section{Matteo MOcA, Figure del surrealismo italiano: Savinio, Delfini, Landolfi}

\section{Michela Rossi Sebastiano}

\section{(2) OpenEdition \\ Sournals}

\section{Edizione digitale}

URL: https://journals.openedition.org/narrativa/486

DOI: $10.4000 /$ narrativa.486

ISSN: 2804-1224

Editore

Presses universitaires de Paris Nanterre

\section{Edizione cartacea}

Data di pubblicazione: 1 décembre 2021

Paginazione: 300-301

ISBN: 978-2-84016-485-2

ISSN: $1166-3243$

\section{Notizia bibliografica digitale}

Michela Rossi Sebastiano, «Matteo moca, Figure del surrealismo italiano: Savinio, Delfini, Landolfi », Narrativa [Online], 43 | 2021, online dal 01 novembre 2021, consultato il 03 novembre 2022. URL: http://journals.openedition.org/narrativa/486 ; DOI: https://doi.org/10.4000/narrativa.486

Questo documento è stato generato automaticamente il 3 novembre 2022

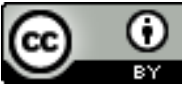

Creative Commons - Attribuzione 4.0 Internazionale - CC BY 4.0

https://creativecommons.org/licenses/by/4.0/ 


\title{
Matteo MOCA, Figure del surrealismo italiano: Savinio, Delfini, Landolfi
}

\author{
Michela Rossi Sebastiano
}

\section{NOTIZIA}

Matteo MocA, Figure del surrealismo italiano: Savinio, Delfini, Landolfi, Lanciano, Carabba, 2020,340 p.

1 Il volume di Matteo Moca ripercorre gli “itinerari surrealisti” di tre autori: Alberto Savinio, Antonio Delfini e Tommaso Landolfi. A differenza di quanto avviene in Francia, il surrealismo italiano non confluisce in un movimento organizzato; ciononostante, come si nota nel primo capitolo, rappresenta un'esperienza letteraria condivisa, rispetto alla quale la rivista Valori plastici, col ruolo di "officina teorica", la metafisica di De Chirico e la psicanalisi di Freud - quindi l'evidenza straniante della rappresentazione e l'indagine dell'inconscio come spazio di significazione simbolica costituiscono importanti nuclei formativi. Successivamente, mantenendo stabile il confronto col movimento francese di cui Breton rappresenta il principale riferimento teorico-letterario, Moca indaga le modalità attraverso le quali ciascun autore imposta la propria forma di surrealtà. I motivi fondamentali della rappresentazione surrealista vale a dire l'insofferenza verso le consuetudini rappresentative, la tendenza a forzare la tenuta referenziale del linguaggio, la tensione verso una dimensione ulteriore, ma non integralmente fantastica, della realtà, e l'importanza della dimensione onirica - sono quindi considerati in relazione al modo in cui vengono accolti, integrati e rielaborati nell'opera degli scrittori.

2 Nel capitolo dedicato a Savinio, Moca si sofferma sulle modalità di raffigurazione della casa (con rimandi alla teoria freudiana), “contrassegnata da impulsi soprannaturali o presenze spirituali" che sono espressione "delle inquietudini e delle preoccupazioni dei protagonisti"; analizza la formulazione saviniana di una mitologia personale, di matrice classica, ed evidenzia inoltre la ricorrenza rappresentativa del momento fra il sonno e 
la veglia, in cui si registra "l'ingresso improvviso della vita dell'inconscio nella vita presente". Nell'opera di Delfini, analizzata nel capitolo successivo, assume un ruolo importante la rielaborazione del flâneur baudelairiano e l'impiego della scrittura automatica come tentativo di scardinare le consuetudini linguistiche e ricalcare così le articolazioni significanti dell'inconscio; centrale anche la "necessità di superare la soglia fisica delle cose [...] per giungere ad un nuovo statuto" di reale, e la trasfigurazione del passato per recuperare, attraverso l'immaginazione, il valore perduto dell'esperienza. Nell'ambito della riflessione linguistica, emerge inoltre "il legame indissolubile e biunivoco tra la parola e la vita, con quest'ultima che si genera e diventa tale attraverso la parola". Landolfi si confronta invece con il "limite tautologico" del linguaggio: la sua scrittura, infatti, è "continua corsa alla precisione dell'espressione nel tentativo impossibile di ricercare il vero nome degli oggetti della realtà". Torna inoltre utile il pensiero di Lacan per approfondire la tecnica landolfiana di "scivolamento del significato sotto il significante".

3 Lo studio di Moca è preciso ed esaustivo: l'analisi testuale, con attenzione puntuale, approfondisce le peculiarità stilistiche di Savinio, Delfini e Landolfi, intercettando le relazioni tra l'opera letteraria e i suoi riferimenti biografici, culturali (l'ambiente intellettuale italiano, la realtà borghese, la psicoanalisi) e filosofici (diretti, come Nietzsche e Schopenhauer, e indiretti - utili ad illuminare i meccanismi letterari come Wittgenstein e Agamben). In questa direzione emerge con chiarezza il carattere irriducibilmente personale dell'esperienza letteraria dei tre autori, e, insieme, la possibilità di individuare una parabola surrealista italiana (legata all'esperienza d'oltralpe), da intendersi come condivisione di interrogativi, tecniche e strumenti attraverso i quali la rappresentazione della realtà si spinge al di là delle consuete soglie di senso. 